\title{
Fibrina rica en plaquetas y su aplicación en periodoncia: revisión de literatura
}

\author{
Platelet-rich fibrin and its application in periodontics: a review of literature \\ Edwin J. Meza-Mauricio ${ }^{1, a}$, María Pía Lecca-Rojas ${ }^{1, b}$, Emil Correa-Quispilaya $^{1, b}$, Katty Ríos-Villasis ${ }^{1, c}$
}

\section{RESUMEN}

La fibrina rica en plaquetas (FRP) es un concentrado plaquetario de segunda generación que nos brinda, en un coágulo o membrana, gran cantidad de factores de crecimiento, leucocitos y citoquinas que se obtienen mediante la centrifugación de sangre autógena. Su fácil preparación y manipulación a diferencia de otros preparados plaquetarios hacen que pueda ser usada en la práctica clínica diaria. La presente revisión bibliográfica tiene como objetivo describir las propiedades biológicas y las aplicaciones clínicas del FRP en la cirugía mucogingival (cobertura radicular) y en el levantamiento del piso del seno maxilar.

\section{PALABRAS CLAVE: Fibrina, recesión gingival, seno maxilar. (DeCS, BIREME)}

\section{SUMMARY}

Platelet rich fibrin (PRF) is a second generation platelet concentrate that delivers, to the clot or membrane, a high concentration of growth factors, leucocytes and cytokines that are obtained through a centrifugation from an autogenous blood sample. The easy preparation and manipulation, in comparison with other platelet preparations, allows using it in the daily clinical practice. This literature review aims to describe the biological properties and the clinical applications of the PRF in muco-gingival surgical procedures and in the maxillary sinus elevation surgery.

KEYWORDS: Fibrin, gingival recession, maxillary sinus. (MeSH, NLM)

Facultad de Odontología, Universidad Inca Garcilaso de la Vega. Lima, Perú. 


\section{INTRODUCCION}

La fibrina rica en plaquetas (FRP), desarrollada en Francia por Choukroun (2001), es un concentrado plaquetario de segunda generación ampliamente utilizado para acelerar la cicatrización de tejidos blandos y duros. Sus ventajas sobre el plasma rico en plaquetas (PRP) incluye la facilidad de su preparación, ya que a diferencia del PRP, esta técnica no requiere de anticoagulante ni trombina bovina (ni ningún otro agente gelificante) (1).

\section{REVISICIÓN DE LITERATURA}

La FRP es un nuevo material de regeneración que contiene gran cantidad de factores de crecimiento, leucocitos, citoquinas y que recoge en una sola membrana de fibrina, a todos los constituyentes de una muestra de sangre favorables para la curación e inmunidad. Su uso en cirugía bucal y maxilofacial, implantología oral y en particular en periodoncia es una tendencia actual e interesante (2). Así pues, la FRP es un biomaterial manipulable, por lo que se puede adaptar sobre la superficie recortándola, es utilizada en procedimientos periodontales, incluyendo recesiones gingivales, aumento del piso sinusal y corrección de defectos intraóseos $(3,4)$.

Protocolo de preparación de la fibrina rica en plaquetas

Para obtener una membrana o coágulo de FRP, la sangre se introduce en tubos de ensayo de $10 \mathrm{ml}$ sin anticoagulante y se centrifuga inmediatamente a 2700 revoluciones por minuto, durante 12 minutos a 280
$\mathrm{G}$ (fuerza gravitacional del centrifugado). Es por ello que se requiere una centrifugadora adecuada (PC-02, Proceso Ltd., Niza, Francia) (5).

A los pocos minutos, la ausencia de anticoagulante permite la activación de la mayoría de plaquetas contenidas en la muestra para desencadenar la cascada de coagulación. El fibrinógeno se concentra al principio en la parte superior del tubo, hasta que el efecto de la circulación de la trombina se transforma en una red de fibrina. El resultado es un coágulo de fibrina que contiene plaquetas situadas en la mitad del tubo, justo entre la capa de glóbulos rojos en la parte inferior y el plasma acelular en la parte superior. Este coágulo se retira del tubo y las células rojas de la sangre se desechan. El coágulo se coloca en la caja de FRP y se cubre con el compresor y la tapa. Esto produce una membrana de fibrina autóloga de bajo costo en aproximadamente un minuto. El exudado recogido en la parte inferior de la caja puede ser utilizado para hidratar materiales de injerto (1-6) (Figuras 1 y 2).

El éxito de esta técnica depende absolutamente del tiempo transcurrido entre la extracción de sangre y su transferencia a la centrifugadora. Por lo tanto, para que la preparación sea clínicamente utilizable. La extracción de sangre y su centrifugación deben ser inmediatas, antes de que se inicie la cascada de coagulación (5).

Propiedades biológicas de la fibrina rica en plaquetas La FRP consta de plaquetas, leucocitos, citoquinas y células madre dentro de una matriz de fibrina. Los leucocitos parecen influir fuertemente en la liberación

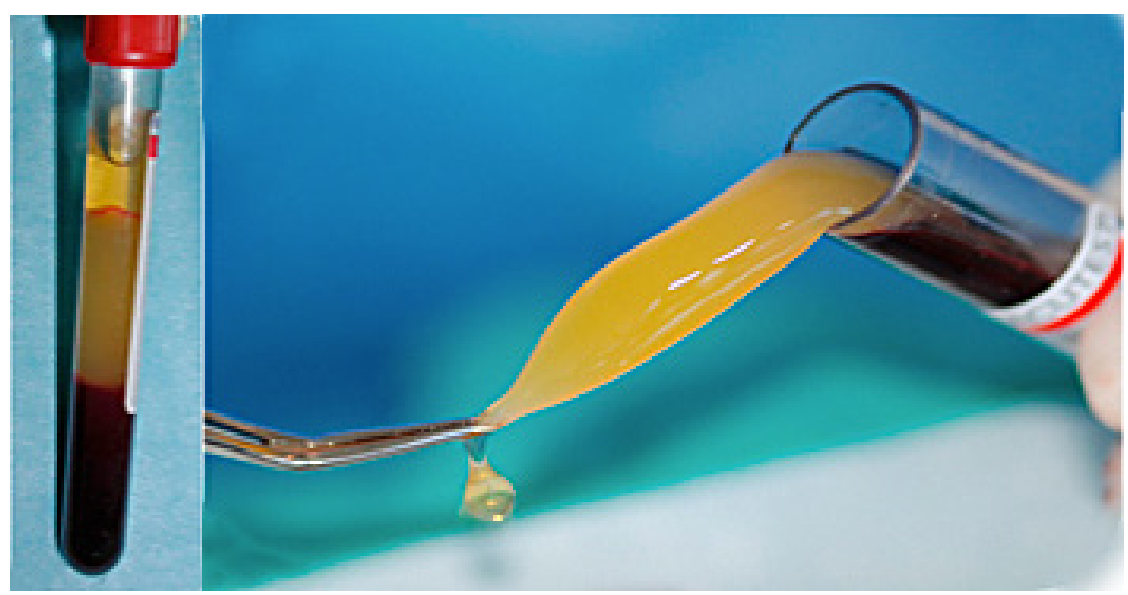

Figura 1. Coágulo de FRP obtenido después de la centrifugación (7). 


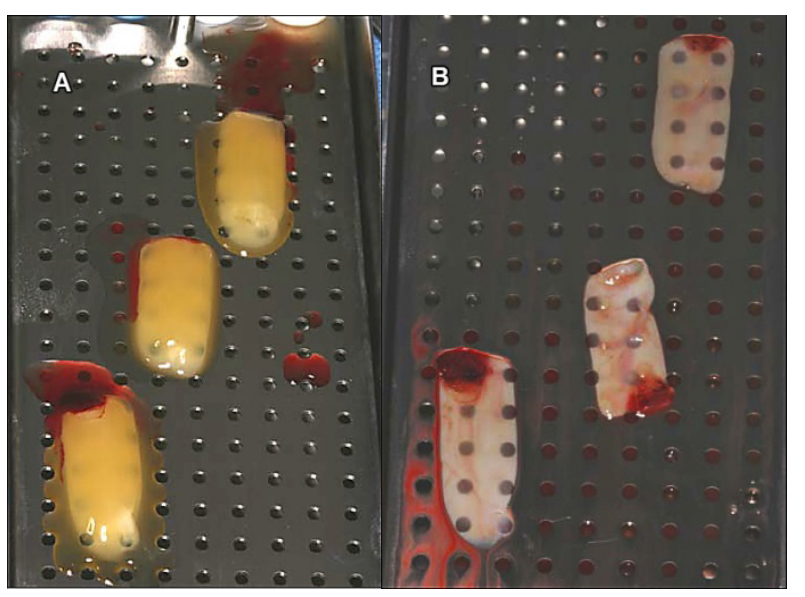

Figura 2. La caja de FRP que se utiliza para crear membranas. A: El coágulo se coloca en la parrilla. B: Se cubre con la tapa y en un minuto se obtiene una membrana de FRP, el exudado de suero se acumula en la parte inferior de la caja, debajo de la rejilla (1).

de factores de crecimiento, en la regulación inmune, en las actividades antiinfecciosas y remodelacion de la matriz durante la cicatrización(8).

Se ha demostrado que después de la centrifugación, el $97 \%$ de las plaquetas y el 50\% de los leucocitos del volumen de sangre original se concentran en la FRP (9).

Dohan y col. $(10,11)$ mostraron la lenta liberación de factores de crecimiento derivados de las plaquetas (FCDP), del factor de crecimiento transformante beta 1 (TGF- $\beta 1$ ), del factor de crecimiento endotelial vascular (FCEV) y de glicoproteínas; como la fibronectina y vitronectina especialmente durante los primeros 7 días. Por su parte, Zumstein y col. (12) observaron que esta liberación continuó hasta un máximo de 28 días y puede ser un complemento útil en la reparacion de tejidos. Devido a estas propiedades la FRP se puede utilizar como un único biomaterial o combinado con diferentes substitutos óseos para acelera la regeneración ósea.

\section{Fibrina rica en plaquetas en recesiones gigivales (Cuadro 1)}

La recesión gingival es el desplazamiento apical del tejido marginal. No sólo constituye uno de los principales problemas estéticos sino que también crea una deformidad funcional por la destrucción de la encía insertada, causa hipersensibilidad y es responsable de la mayor incidencia de caries radicular (13).

Desde mediados del siglo XX, las diferentes técnicas como injertos autólogos libres, injertos pediculares incluyendo colgajos rotacionales, colgajos de avance coronal (CAC), colgajos semilunares; han sido utilizados para cubrir las superficies radiculares desnudas $(14,15)$. Sin embargo, estas técnicas requieren de un lugar donante, que por lo general es la zona palatina con lo cual aumenta la morbilidad post operatoria (16). Además, si el paciente tiene el tejido

Cuadro 1. Aplicación de fibrina rica en plaquetas en recesiones gingivales.

\begin{tabular}{|c|c|c|c|c|}
\hline Recesiones gingivales & Diseño de estudio & Población & Intervención & Conclusiones \\
\hline Aroca y col. (2009)(19) & $\begin{array}{l}\text { Ensayo clínico } \\
\text { aleatorizado }\end{array}$ & $\begin{array}{l}20 \text { pacientes } \\
\text { que presentaban } \\
\text { recesiones gingivales } \\
\text { clase I y II de Miller. }\end{array}$ & $\begin{array}{l}\text { - Técnica de CAC } \\
\text { con FRP. } \\
\text { - Técnica de CAC. }\end{array}$ & $\begin{array}{l}\text { - La adición de una membrana de } \\
\text { FRP proporciona una cobertura de } \\
\text { la raíz inferior, pero una ganancia } \\
\text { adicional en el ancho de la encía } \\
\text { queratinizada y biotipo gingival a los } \\
6 \text { meses, comparado con el control. }\end{array}$ \\
\hline $\begin{array}{c}\text { Jankovic y col. (2010) } \\
\text { (20) }\end{array}$ & $\begin{array}{l}\text { Estudio } \\
\text { comparativo }\end{array}$ & $\begin{array}{l}20 \text { pacientes } \\
\text { que presentaban } \\
\text { recesiones gingivales } \\
\text { clase I y II de Miller. }\end{array}$ & $\begin{array}{l}\text { - Técnica de CAC } \\
\text { con FRP. } \\
\text { - Técnica de CAC } \\
\text { con DME }\end{array}$ & $\begin{array}{l}\text { - La cobertura en el grupo de FRP } \\
\text { fue de } 65 \% \text { y } 60 \% \text { en el grupo de } \\
\text { DME. } \\
\text { - La intensidad del dolor fue } \\
\text { estadísticamente diferente entre los } \\
\text { grupos durante los primeros } 5 \text { días, a } \\
\text { favor del grupo con FRP. }\end{array}$ \\
\hline $\begin{array}{c}\text { Eren y Atilla (2013) } \\
\text { (21) }\end{array}$ & $\begin{array}{l}\text { Ensayo clínico } \\
\text { aleatorizado }\end{array}$ & $\begin{array}{l}22 \text { pacientes } \\
\text { que presentaban } \\
\text { recesiones gingivales } \\
\text { clase I y II de Miller. }\end{array}$ & $\begin{array}{l}\text { - Técnica de CAC } \\
\text { con FRP. } \\
\text { - Técnica de FRP con } \\
\text { ITCS. }\end{array}$ & $\begin{array}{l}\text { - El porcentaje de cobertura de la } \\
\text { raíz en el grupo con FRP fue de } \\
92,7 \% \text { y en el grupo control fue de } \\
94,2 \% \text {. } \\
\text { - Las recesiones gingivales } \\
\text { localizadas pueden ser tratadas con } \\
\text { éxito con la CAC + FRP así como } \\
\text { CAC + ISTC. }\end{array}$ \\
\hline
\end{tabular}


del paladar delgado, es difícil conseguir suficiente tejido donante y un sitio donante adicional puede ser necesario cuando múltiples defectos están presentes, dando lugar a múltiples cirugías (17).

Una innovación en la odontología es el uso de concentrados plaquetarios de segunda generación, como la fibrina rica en plaquetas, que contiene factores de crecimiento y propiedades de cicatrización para los procedimientos de cobertura radicular (18).

Estudios realizados en los últimos años $(19,20,21)$, demuestran gran versatilidad y eficacia de este biomaterial para el éxito clínico en el tratamiento de las recesiones gingivales. Así, el 2009, Aroca y col. (19) evaluaron la FRP en recesiones gingivales, observando que la cobertura radicular respecto a un colgajo de avance coronal (CAC) fue menor en el grupo de FRP. Sin embargo, obtuvieron una mayor ganancia en el biotipo gingival y ancho de encía queratinizada.

Así mismo, el año 2010, Jankovi y col. (20) realizaron un estudio donde no se encontró diferencia significativa entre la eficacia clínica de la FRP y un derivado de la matriz del esmalte (DME) para el tratamiento de recesiones gingivales (Miller I y II); a los 12 meses post tratamiento la cobertura radicular fue similar, demostrando que ambas técnicas tienen un buen pronóstico para dicho tratamiento.

Continuando en la misma línea de investigación, Eren y Atilla (21) mediante un ensayo clínico en el año 2013, evaluaron la eficacia de la FRP en comparación con un injerto de tejido conectivo subepitelial (ITCS) para el tratamiento de recesiones gingivales localizadas (Miller I y II), sin obtenerse diferencia estadísticamente significativa. Concluyendo, que las recesiones gingivales localizadas pueden ser tratadas con éxito con el CAC + FRP, así como CAC + ISTC.

\section{Fibrina rica en plaquetas en levantamiento del piso del seno maxilar (Cuadro 2)}

La zona edéntula posterior de la maxila, generalmente proporciona una cantidad limitada de volumen óseo debido a una atrofia del reborde y la neumatización del seno maxilar. Estas limitaciones anatómicas representan desafíos que pueden afectar el éxito de la oseointegración y la confección de una restauración implantosoportada funcional y estética (22).

La elevación del piso del seno maxilar es una técnica quirúrgica empleada para aumentar el volumen óseo, por lo general puede realizarse de acuerdo a dos

Cuadro 2. Aplicación de fibrina rica en plaquetas en levantamiento del piso de seno maxilar.

\begin{tabular}{|c|c|c|c|c|}
\hline $\begin{array}{l}\text { Levantamiento de } \\
\text { seno maxilar }\end{array}$ & Diseño de estudio & Población & Intervención & Conclusiones \\
\hline Mazor y col. (2009) (30) & Serie de casos & $\begin{array}{l}20 \text { pacientes con } 25 \\
\text { elevaciones laterales } \\
\text { del seno, con la } \\
\text { colocación inmediata } \\
\text { de implantes. }\end{array}$ & $\begin{array}{l}\text { - Coagulo de } \\
\text { FRP como único } \\
\text { material de relleno } \\
\text { y membrana de } \\
\text { FRP. }\end{array}$ & $\begin{array}{l}\text { - La ganancia ósea final siempre fue } \\
\text { muy significativa entre } 7 \text { y } 13 \mathrm{~mm} \text {. } \\
\text { - La FRP y su uso sistemático } \\
\text { durante una elevación de seno parece } \\
\text { una opción relevante, en particular } \\
\text { para la protección de la membrana } \\
\text { de Schneider. }\end{array}$ \\
\hline Gassling y col. (2013) (24) & $\begin{array}{c}\text { Estudio } \\
\text { comparativo }\end{array}$ & $\begin{array}{l}6 \text { pacientes con } \\
12 \text { elevaciones } \\
\text { laterales del seno, } \\
\text { con la colocación de } \\
\text { implantes dentales, } \\
\text { cinco meses después. }\end{array}$ & $\begin{array}{l}\text { - Hueso autólogo } \\
\text { y Bio-Oss }{ }^{\circledR} \text { con } \\
\text { membrana de FRP. } \\
\text { - Hueso autólogo } \\
\text { y Bio-Oss }{ }^{\circledR} \text { con } \\
\text { membrana Bio- } \\
\text { Gide } \AA \text {. }\end{array}$ & $\begin{array}{l}\text { - Se demostró que la cobertura } \\
\text { de la ventana lateral del seno } \\
\text { con la membrana de FRP (grupo } \\
\text { experimental) y la membrana de } \\
\text { Bio-Gide } ₫ \text { (grupo control) dieron } \\
\text { lugar a una cantidad similar de } \\
\text { formación de hueso vital y sustitutos } \\
\text { óseos residuales. }\end{array}$ \\
\hline Tajima y col. (2013) (31) & Serie de casos & $\begin{array}{c}6 \text { pacientes con } 9 \\
\text { elevaciones laterales } \\
\text { del seno, con la } \\
\text { colocación inmediata } \\
\text { de implantes. }\end{array}$ & $\begin{array}{l}\text { - FRP como único } \\
\text { material de injerto. }\end{array}$ & $\begin{array}{l}\text { - La altura de hueso residual media } \\
\text { entre el suelo del seno y la cresta } \\
\text { alveolar fue } 4,28 \pm 1,00 \mathrm{~mm} \text { antes de } \\
\text { la cirugía y } 11.8 \pm 1.67 \mathrm{~mm} \text { después. } \\
\text { - La elevación de seno con la } \\
\text { colocación simultánea de implantes } \\
\text { usando FRP como el único material } \\
\text { de relleno puede promover la } \\
\text { regeneración ósea natural. }\end{array}$ \\
\hline
\end{tabular}




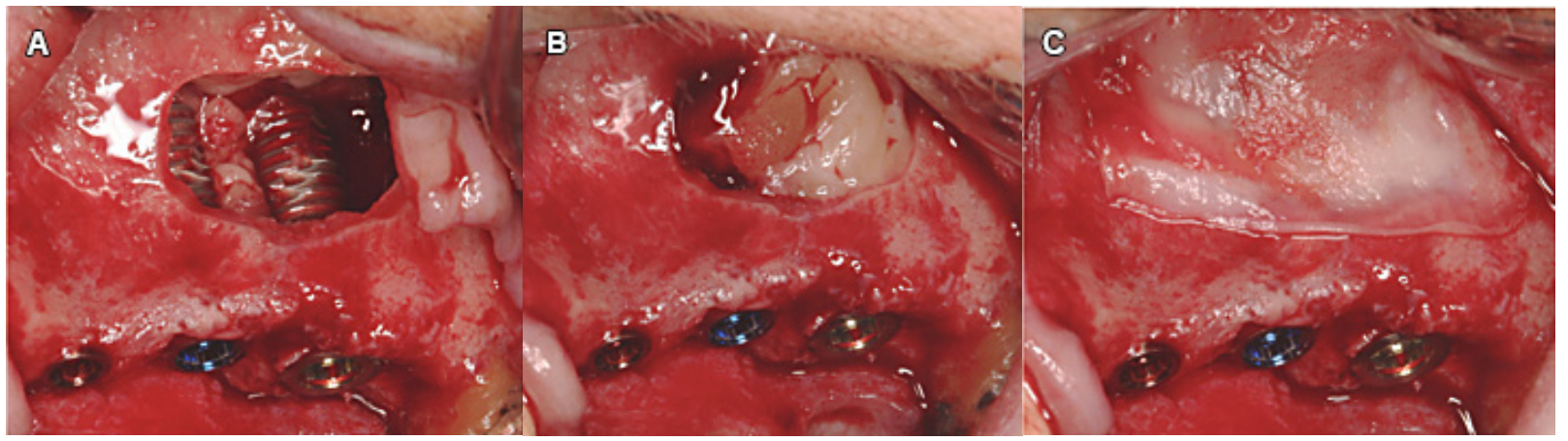

Figura 3. A: Implantes ubicados para mantener la membrana sinusal en una posición alta y sirviendo como "estacas". B: La cavidad del seno maxilar, se llenó con coágulos de FRP. C: Membrana de PRF que se utilizó para cubrir la osteotomía lateral (30).

técnicas. La primera, el abordaje a través del reborde alveolar maxilar, fue presentada por primera vez por Tatum en el año 1977; y la segunda, el abordaje quirúrgico a través de una osteotomía lateral del seno maxilar, fue reportada por Boyne y James en el año $1980(23)$.

Durante mucho tiempo el material de elección en procedimientos de levantamiento de seno maxilar ha sido el injerto de hueso autólogo debido a sus propiedades osteoinductivas y osteoconductivas; sin embargo, sus principales desventajas son la morbilidad del sitio donante, la restricción de tamaño y su reabsorción ósea (24).

Actualmente, existen diversos substitutos óseos como los aloinjertos que son injertos de la misma especie del receptor, xenoinjertos o injertos de una especie diferente de la especie original del receptor, y los aloplásticos o biomateriales sintéticos. Siendo posible también utilizar una combinación de estos diferentes tipos (25).

Lundgren y col. $(26,27)$ informaron de un nuevo método para la elevación del seno maxilar el cual consiste en el uso de sangre como único material de relleno. El estudio mostró que existe un gran potencial para la curación y la formación de hueso en el seno maxilar sin el uso de injertos óseos adicionales o sustitutos óseos. Sugirieron, que el uso de sustitutos óseos durante el aumento del seno maxilar no es absolutamente necesario porque el coágulo de sangre natural dentro del espacio del seno maxilar es capaz de promover la regeneración del hueso.

La elevación de seno se lleva a cabo por la técnica de ventana lateral, con la colocación simultánea de implantes; entonces, el espacio entre la membrana sinusal y el hueso maxilar se llena con sangre total, para estimular la formación ósea, basado en el concepto de regeneración ósea guiada. Los implantes sirven como "estacas" que mantienen la membrana sinusal en una posición elevada y el coágulo de sangre que llena el espacio muerto sirve como un andamio para la formación de hueso. Esto conduce a la regeneración natural de hueso alrededor de los implantes. Sin embargo, a menudo es difícil llenar la cavidad sinusal con un coágulo de sangre estabilizada. El uso de preparaciones de sangre, como de FRP puede ser una opción interesante para mejorar este enfoque $(28,29)$ (Figura 3).

Estudios realizados por Mazor y col. (30) y Tajima y col. (31) evaluaron la eficacia de los coágulos y membranas de FRP como único material de relleno en la elevación de seno maxilar con la colocación simultanea de implantes, obteniendo una ganancia ósea final siempre muy significativa. Encontrando histológicamente hueso vital y bien organizado.

Asímismo, Gassling y col. (24) el año 2013, evaluaron el efecto de la FRP como membrana de barrera en el sitio de la osteotomía lateral en la elevación de seno. Los senos fueron injertados con hueso autólogo y material óseo sustituto (Bio-Oss ${ }^{\circledR}$ ), cubriéndose en un diseño de boca dividida con una membrana de FRP o una membrana de colágeno (Bio-Gide $\left({ }^{\circledR}\right)$, encontrándose que histológicamente la calidad ósea era parecida en ambos sitios de los senos injertados.

\section{CONCLUSIONES}

La fibrina rica en plaquetas (PRF) es un concentrado plaquetario de fácil manipulación y viable para su uso 
en la práctica clínica. En el tratamiento de recesiones gingivales la FRP evita la necesidad de tomar injertos de un área donante en el paladar disminuyendo así la morbilidad post operatoria. Se ha observado que el porcentaje de cobertura radicular es inferior con la FRP, en comparación al injerto de tejido conectivo subepitelial (ITCS) en el tratamiento de recesiones gingivales. Y comparado con el colgajo de reposición coronal, la FRP tiene la ventaja al aumentar el biotipo gingival y ancho de encía queratinizada. La FRP como biomaterial de relleno en el levantamiento del piso del seno maxilar es una opción relevante, ya que los estudios disponibles en la literatura demuestran topográficamente e histológicamente que promueve la regeneración ósea.

\section{Correspondencia}

Edwin J. Meza-Mauricio

Alcanfores 427 Dpto - 203 B, Miraflores.

Lima,Perú.

Correo electrónico: jonathanmeza.m@hotmail.com

\section{REFERENCIAS BIBLIOGRAFICAS}

1. Toffler M, Toscano N, Holtzclaw D, Corso MD, Dohan Ehrenfest D. Introducing Choukroun's platelet rich fibrin (PRF) to the reconstructive surgery milieu. J Implant Adv Clin Dent. 2009; 1(6):21-30.

2. Montanari M, Callea M, Yavuz I, Maglione M. A new biological approach to guided bone and tissue regeneration. BMJ. 2013; 9 (2):1-3.

3. Sharma A, Pradeep A. Autologous platelet-rich fibrin in the treatment of mandibular degree II furcation defects: a randomized clinical trial. J Periodontol. 2011; 82(10):1396-403.

4. Sharma A, Pradeep A. Treatment of 3-wall intrabony defects in patients with chronic periodontitis with autologous platelet-rich fibrin: a randomized controlled clinical trial. J Periodontol. 2011; 82(12):1705-12.

5. Sunitha V, Munirathnam E. Platelet-rich fibrin: evolution of a second-generation platelet concentrate. Indian J Dent Res. 2008; 19(1):42-6.

6. Navin M, Isha N, Neelam M. Platelet rich fibrin mediated revitalization of immature necrotic tooth. Contemp Clin Dent. 2013; 4(3):412-5.

7. Eren G, Atilla G. Platelet-rich fibrin in the treatment of bilateral gingival recessions. Clinical Advances in Periodontics. 2012; 2(3):154-60.

8. Leigha R. Potential of platelet rich fibrin in regenerative periodontal therapy: literature review. Can J Dent Hyg. 2013; 47(1):33-7.

9. Bölükbaşı N, Yeniyol S, Tekkesin M, Altunatmaz K.
The use of platelet-rich fibrin in combination with biphasic calcium phosphate in the treatment of bone defects: a histologic and histomorphometric study. Curr Ther Res Clin Exp. 2013; 75:15-21.

10. Dohan D, Bielecki T, Jimbo R. Do the fibrin architecture and leukocyte content influence the growth factor release of platelet concentrates? An evidence-based answer comparing a pure platelet-rich plasma (P-PRP) gel and a leukocyte and platelet-rich fibrin (L-PRF). Curr Pharm Biotechnol. 2012; 13(7):1145-52.

11. Dohan D, de Peppo M, Doglioli P. Slow release of growth factors and thrombospondin-1 in Choukroun's platelet-rich fibrin (PRF): a gold standard to achieve for all surgical platelet concentrates technologies. Growth Factors. 2009; 27(1):63-9.

12. Zumstein A, Berger S, Schober M. Leukocyte- and platelet-rich fibrin (L-PRF) for long-term delivery of growth factor in rotator cuff repair: review, preliminary results and future directions. Curr Pharm Biotechnol. 2012; 13(7):1196-1206.

13. Bhaumik N, Neeta V, Mali J. Coronally positioned flap for root coverage: comparison between smokers and nonsmokers. J Int Oral Health. 2013; 5(2):21-7.

14. Gülnihal E, Gül A. Platelet-rich fibrin in the treatment of bilateral gingival recessions. Clinical Advances in Periodontics. 2012; 2(3):154-60.

15. Anilkumar K, Geetha A, Ramakrishnan T, Vijayalakshmi R, Pameela E. Platelet-rich-fibrin: a novel root coverage approach. J Indian Soc Periodontol. 2009; 13(1):50-4.

16. Ardila M. Aplicación clínica de la matriz dérmica acelular para prevenir recesiones gingivales. Periodon Implantol. 2009; 21(1):27-34.

17. Cairo F, Pagliaro U, Nieri M. Treatment of gingival recession with coronally advanced flap procedures: a systematic review. J Clin Periodontol. 2008; 35(8):13662.

18. Rajan P, Ande S, Pavaluri A, Meganderao N, Chetan $\mathrm{K}$, Annaji S. A split mouth randomized controlled study to evaluate the adjunctive effect of platelet-rich fibrin to coronally advanced flap in Miller's class-I and II recession defects. J Indian Soc Periodontol. 2013; 17(5):631-6.

19. Aroca S, Keglevich T, Barbieri B, Gera I, Etienne D. Clinical evaluation of a modified coronally advanced flap alone or in combination with a platelet-rich fibrin membrane for the treatment of adjacent multiple gingival recessions: a 6-month study. J Periodontol. 2009; 80(2):244-52.

20. Jankovic S, Aleksic Z, Milinkovic I, Dimitrijevic B. The coronally advanced flap in combination with platelet-rich fibrin (PRF) and enamel matrix derivative in the treatment of gingival recession: a comparative study. Eur J Esthet Dent. 2010; 5 (3):26073. 
21. Eren G, Atilla G. Platelet-rich fibrin in the treatment of localized gingival recessions: a split-mouth randomized clinical trial. Clin Oral Investig. 2013;18 (7):1740-8.

22. Ferrigno N, Laureti M, Fanali S. Dental implants placement in conjunction with osteotome sinus floor elevation: a 12-year life- table analysis from a prospective study on 588 ITI implants. Clin Oral Implants Res. 2006; 17(2):194-205.

23. Boyne P, James R. Grafting of the maxillary sinus floor with autogenous marrow and bone. J Oral Surg. 1980; 38(8):613-16.

24. Gassling V, Purcz N, Braesen J, Will M, Gierloff M, Behrens E, Açil Y, Wiltfang J. Comparison of two different absorbable membranes for the coverage of lateral osteotomy sites in maxillary sinus augmentation: a preliminary study. J Craniomaxillofac Surg. 2013; 41(1):76-82.

25. Runzer E, Arrascue M, Ccahuana V. Levantamiento del piso de seno maxilar mediante la técnica de osteótomos: reporte de caso. Rev Estomatol Herediana. 2011; 21(3):150-154.

26. Lundgren S, Andersson S, Gualini F, Sennerby L. Bone reformation with sinus membrane elevation: a new surgical technique for maxillary sinus floor augmentation. Clin Implant Dent Relat Res. 2004; 6(3):165-73.

27. Lundgren S, Cricchio G, Palma V, Salata L, Sennerby
L. Sinus membrane elvation and simultaneous insertion of dental implants: a new surgical technique in maxillary sinus floor augmentation. Periodontol. 2000. 2008; 47:193-205.

28. Dohan D, Rasmusson L, Albrektsson T. Classification of platelet con- centrates: from pure platelet-rich plasma (P-PRP) to leucocyte and platelet rich fibrin (L-PRF). Trends Biotechnol. 2009; 27(3):158-67.

29. Sohn D, Heo J, Kwak D, Kim D, Kim J, Moon J, Lee J. Bone regeneration in the maxillary sinus using an autologous fibrin-rich block with concentrated growth factors alone. Implant Dent. 2011; 20(5):38995.

30. Mazor Z, Horowitz RA, Del Corso M, Prasad H, Rohrer M, Dohan D. Sinus floor augmentation with simultaneous implant placement using Choukroun's platelet-rich fibrinas the sole grafting material: a radiologic and histologic study at 6 months. J Periodontol. 2009; 80(12):2056-64.

31. Tajima N, Ohba S, Sawase T, Asahina I. Evaluation of sinus floor augmentation with simultaneous implant placement using platelet-rich fibrin as sole grafting material. Int J Oral Maxcillofac Impl. 2013; 28 (1):7783.

Recibido: 01/02/2014

Aceptado: 15/04/2014 